CAHIER DE RECHERCHE \#1714E

WORKING PAPER \#1714E

Département de science économique

Department of Economics

Faculté des sciences sociales

Faculty of Social Sciences

Université d'Ottawa

University of Ottawa

\title{
Natural Resource Extraction in a Federation*
}

\author{
Robin Boadway ${ }^{\dagger}$, Motohiro Sato, ${ }^{\ddagger}$ and Jean-François Tremblay, ${ }^{\S}$
}

\section{October 2017}

\footnotetext{
${ }^{*}$ Prepared for the Festschrift in honour of Hans-Werner Sinn. We explore themes to which Hans-Werner made important contributions early in his career, including natural resource extraction and dynamic policy analysis. We have benefited from insightful comments by the referee.

${ }^{\dagger}$ Department of Economics, Queen's University, Dunning Hall, 94 University Avenue, Kingston, Ontario, Canada, K7L 3N6; e-mail: boadwayr@econ.queensu.ca

‡ Faculty of Economics, Hitotsubashi University, 2-1 Naka, Kunitachi, Tokyo 186-8601, Japan; e-mail: satom@econ.hit-u.ac.jp

$\S$ Department of Economics, University of Ottawa, 120 University Private, Ottawa, Ontario, Canada, K1N 6N5; email: Jean-Francois.Tremblay@uottawa.ca
} 


\begin{abstract}
We analyze a natural resource extraction problem in a two-region economy with mobile labour. One of the regions produces only manufacturing goods while the other produces agriculture and extracts a nonrenewable natural resource. The manufacturing sector exhibits increasing returns-to-scale if the level of production is sufficiently high. There are multiple equilibrium allocations of labour towards which the economy may converge in the long-run depending on the initial stock of natural resource and the initial distribution of labour. Under decentralized resource management, there is a tendency to over-extract the resource relative to the constrained federal optimum, which tends to enlarge the set of initial conditions under which the economy converges to the low-income equilibrium. The optimal path of extraction from the perspective of the federation satisfies a modified Hotelling's rule that takes into account the impact of resource extraction on manufacturing production.
\end{abstract}

Key words: Natural resource extraction, decentralization, inter-regional mobility.

JEL Classification: H70, Q32, Q33. 


\section{Introduction}

It is well-known that increases in a country's resource wealth do not necessarily translate into sustained growth and higher living standards (e.g. Sachs and Warner, 2001; van der Ploeg, 2011). Natural resource wealth can turn into a curse if resource extraction results in a reallocation of production factors away from sectors with high productivity growth, or if the rents derived from non-renewable resource exploitation are not optimally invested in other productive assets such as public infrastructure. In this paper, we examine how the potential for a resource curse may be exacerbated in a federal setting with decentralized natural resource management and inter-regional labour mobility.

There are various mechanisms by which natural resource exploitation can have a negative impact on aggregate production. Krugman $(1987 ; 1991)$ and Sachs and Warner (1999) examined how a resource boom can lower aggregate productivity growth by attracting factors of production away from sectors where production involves learning-by-doing or increasing returns-to-scale. Sachs and Warner (2001) provide empirical evidence consistent with this explanation of the resource curse. Corden and Neary (1982) showed how a resource boom may reduce the competitiveness of traded-goods sectors by inducing a real appreciation, ultimately leading to lower aggregate production. A vast literature, recently surveyed by van der Ploeg (2011), has examined how natural resource exploitation may reduce aggregate growth because of rent-seeking behaviour, corruption and conflict. Our analysis focuses on additional sources of inefficiencies that can arise because of decentralization in the management of natural resource exploitation. Our paper is related to Raveh (2012) who examined how labour mobility might alleviate Dutch disease effects in a federal setting, although his analysis focuses mainly on tax competition incentives.

Our analysis is also related to the fiscal federalism literature that focuses on efficiency in the allocation of labour across regions (e.g. Flatters, Henderson and Miezskowski, 1973; Boadway and Flatters, 1982, Gordon, 1983; Albouy, 2012), and on the existence of multiple equilibrium allocations of labour in the presence of agglomeration effects (e.g. Mitsui and Sato, 2001; Baldwin and Krugman, 2004; Bucovetsky, 2005). We contribute to this literature by introducing a dynamic non-renewable resource extraction problem in a federal setting with labour mobility. 
We consider a dynamic two-region model with a natural resource sector, a manufacturing sector and an agricultural sector. The manufacturing sector is located in one region whereas the natural resource and agricultural sectors are located in the other. The manufacturing sector exhibits increasing returns-to-scale and requires public infrastructure provided by the regional government. The rate of extraction of the non-renewable resource is controlled by the government of the resource region. There is labour mobility across regions, although migration requires time so per capita incomes are only gradually equalized across regions. In this setting, the analysis shows that there are multiple equilibrium allocations of labour towards which the economy may converge in the long-run. Initial conditions with respect to the stock of resources and the allocation of labour across regions determines the equilibrium towards which the economy will converge. An increase in the price of the natural resource or a decrease in the share of resource rents captured by producers tend to shrink the set of initial conditions under which the economy converges to the high-income equilibrium. Under decentralization, the extraction decision of the government of the resource region is distorted relative to the constrained federal optimum, which tends to make convergence to the inefficient long-run equilibrium more likely. We derive a modified Hotelling rule for optimal resource extraction that takes into account the fact that resource extraction shifts labour away from the manufacturing sector thereby diluting the gains from economies of scale.

\section{The Model}

There are two regions $M$ and $R$, each specializing in different types of production. Region $M$ produces manufacturing goods using one of two possible technologies: a traditional one with constant returns to scale or a modern one with increasing returns. The modern technology requires public infrastructure and is only adopted if the manufacturing sector reaches a minimum size. Public infrastructure is provided by the regional government and is financed with a labour income tax. Manufacturing goods are tradable. In region $R$, there is an agricultural sector that operates under a constant returns technology, as a well as a natural resource sector. ${ }^{1}$ Agricultural output is tradable across regions but non-tradable internationally. The natural resource is non-renewable and all resource production is sold 
on international markets. Resource extraction is controlled by the government of region $R$, for example, by issuing permits. The economy is assumed to be small so manufacturing goods and natural resources are sold at given world prices. There is imperfect interregional mobility in the sense that a reallocation of labour across regions requires time. However, labour is perfectly mobile between the traditional and modern technology in region $M$ and between agriculture and natural resources in region $R$.

\section{Manufacturing Sector in Region M}

The production structure in manufacturing follows that found in Krugman (1991), Sachs and Warner (1999) and Murphy, Shleifer and Vishny (1989). Under the traditional technology, manufacturing production at time $t$ is $\tilde{X}_{t}=\mu L_{t}^{M}$, where $L_{t}^{M}$ is the amount of labour in region $M$. With perfect competition in the labour market and the price of manufacturing goods normalized to unity, the wage rate of workers under the traditional technology equals the marginal product of labour, i.e. $\tilde{w}_{t}^{M}=\mu$.

Under the modern technology, final manufacturing goods $X_{t}$ are produced using a continuum of intermediate goods as inputs according to

$$
X_{t}=\left(\int^{N_{t}}\left(x_{t}^{i}\right)^{\sigma} d i\right)^{\frac{1}{\sigma}} G_{t}^{\alpha}
$$

where $x_{t}^{i}$ is the $i$ th intermediate good. The range of intermediate goods spans the interval $\left[0, N_{t}\right]$, and the number of producers $N_{t}$ is determined endogenously. $G_{t}$ is the level of public infrastructure provided in region $M$, and $0<\sigma, \alpha<1$. There is monopolistic competition among producers of intermediate goods and instantaneous free entry.

Demand for intermediate goods at time $t$ will solve:

$$
\max _{\left\{x_{t}^{i}\right\}}\left(\int^{N_{t}}\left(x_{t}^{i}\right)^{\sigma} d i\right)^{\frac{1}{\sigma}} G_{t}^{\alpha}-\int^{N_{t}} p_{t}^{i} x_{t}^{i} d i
$$

where $p_{t}^{i}$ is the price of the $i$ th intermediate good. The solution to this problem gives:

$$
x_{t}^{i}=\left(\int^{N_{t}}\left(x_{t}^{i}\right)^{\sigma} d i\right)^{\frac{1}{\sigma}} G_{t}^{\frac{\alpha}{1-\sigma}}\left(p_{t}^{i}\right)^{\frac{-1}{1-\sigma}}
$$

Thus, the demand for $x_{t}^{i}$ is increasing in infrastructure $G_{t}$ and decreasing in price $p_{i}$. 
The production of intermediate goods uses only labour. The amount of labour required to produce $x_{t}^{i}$ units of intermediate good $i$ is:

$$
\ell_{t}^{i}=a x_{t}^{i}+b
$$

Given the presence of the fixed cost $b$, average costs in the production of each intermediate goods are declining. The problem of intermediate goods producers is $\max _{\left\{p_{t}^{i}\right\}} \quad p_{t}^{i} x_{t}^{i}-w_{t}^{M} \ell_{t}^{i}$, where $w_{t}^{M}$ is the wage rate. Using (2) and (3) to substitute for $x_{t}^{i}$ and $\ell_{t}^{i}$, and noting that producers take $\int^{N_{t}}\left(x_{t}^{i}\right)^{\sigma} d i$ as given, the solution to this problem yields:

$$
p_{t}^{*}=\frac{a}{\sigma} w_{t}^{M}
$$

All intermediate goods have the same equilibrium price and therefore $x_{t}^{i}=x_{t}$ and $\ell_{t}^{i}=\ell_{t}$ for all $i$. Using (3) and (4), the profit of each intermediate good producer $\pi_{t}$ is:

$$
\pi_{t}=p_{t} x_{t}-w_{t} \ell_{t}=\left(\frac{1-\sigma}{\sigma} a x_{t}-b\right) w_{t}^{M}
$$

Free entry of intermediate good producers implies that profits are zero, leading to:

$$
x_{t}=\bar{x}=\frac{\sigma}{1-\sigma} \cdot \frac{b}{a}
$$

With the manufacturing sector producing under the modern technology, equilibrium in the labour market is such that total demand for labour by intermediate good producers equals total labour supply in region $M$, i.e. $L_{t}^{M}=N_{t}(a \bar{x}+b)=N_{t}(b / 1-\sigma)$. Therefore, the number of intermediate good producers at time $t$ is:

$$
N_{t}=\frac{1-\sigma}{b} L_{t}^{M}
$$

Substituting (4) and (6) in (2), using $x_{t}^{i}=\bar{x}$ and solving for the wage rate, we get:

$$
w_{t}^{M}\left(L_{t}^{M}, G_{t}\right)=D G_{t}^{\alpha}\left(L_{t}^{M}\right)^{\frac{1-\sigma}{\sigma}} \quad \text { where } \quad D \equiv \frac{\sigma}{a}\left(\frac{1-\sigma}{b}\right)^{\frac{1-\sigma}{\sigma}}
$$

Thus, the wage rate is increasing in the size of the labour force, reflecting economies of scale in production. Since the level of production of each intermediate good is fixed, an 
increase in the size of the labour force results in an increase in the variety of intermediate goods. In turn, given that intermediate goods are complementary in the production of final goods, an increase in the variety of intermediate goods raises the productivity of all intermediate goods in final goods production. Higher productivity raises the price of intermediate goods and the wage rate.

With $x_{t}^{i}=\bar{x}$, final goods production is:

$$
X_{t}=\left(N_{t} \bar{x}^{\sigma}\right)^{\frac{1}{\sigma}} G_{t}^{\alpha}=\left(\frac{1-\sigma}{b}\right)^{\frac{1}{\sigma}} \bar{x} G_{t}^{\alpha}\left(L_{t}^{M}\right)^{\frac{1}{\sigma}}=D G_{t}^{\alpha}\left(L_{t}^{M}\right)^{\frac{1}{\sigma}}=w_{t}^{M}\left(L_{t}^{M}, G_{t}\right) L_{t}^{M}
$$

Final goods production equals total wages, and therefore, profits of final goods producers equal zero, as do those of intermediate goods producers. Producers in the final goods sector take as given the number of varieties of intermediate goods. From their perspective, production exhibits constant returns to scale. As a result, the costs of purchasing intermediate goods in equilibrium fully exhaust the value of production. Since intermediate goods production uses only labour, the value of final goods will be equal to total wages.

The government in region $M$ levies a wage tax at rate $\tau_{M}$ to finance investment in public infrastructure. Assume for simplicity that government current expenditures are restricted to equal current revenues. Then, the government budget constraint is $G_{t}=$ $\tau_{M} w_{t}^{M} L_{t}^{M}=\tau_{M} X_{t}$. Using this, (7) and (8) can be rewritten as:

$$
w_{t}^{M}=D^{\frac{1}{1-\alpha}} \tau_{M}^{\frac{\alpha}{1-\alpha}}\left(L_{t}^{M}\right)^{\gamma}, \quad \text { and } \quad X_{t}=D^{\frac{1}{1-\alpha}} \tau_{M}^{\frac{\alpha}{1-\alpha}}\left(L_{t}^{M}\right)^{\gamma+1}
$$

where $\gamma \equiv 1 /(\sigma(1-\alpha))-1$. Since $0<\alpha, \sigma<1$, we have $\gamma>0$, so $w_{t}^{M}$ will increase with $L_{t}^{M}$, and $X_{t}$ is convex in $L_{t}^{M}$. As well, we assume that $\gamma<1$.

The technology used in manufacturing production in region $M$ will be the one under which the productivity of workers is highest, which in turn depends on the scale of production. Thus, we have the following:

Lemma 1: Manufacturing production will operate under the modern technology if

$$
\left(1-\tau_{M}\right) w_{t}^{M}=K\left(L_{t}^{M}\right)^{\gamma} \geqslant \mu, \quad \text { where } \quad K \equiv\left(1-\tau_{M}\right) D^{\frac{1}{1-\alpha}} \tau_{M}^{\frac{\alpha}{1-\alpha}}
$$

Let $\widehat{L}_{t}^{M}=\widehat{L}^{M}\left(\tau_{M}\right)$ be the size of the labour force in region $M$ at which the condition 
above holds with equality. ${ }^{2}$ The after-tax income of residents in region $M$ is therefore:

$$
I_{t}^{M}\left(L_{t}^{M}, \tau_{M}\right)=\left\{\begin{array}{ccc}
\mu & & L_{t}^{M}<\widehat{L}_{M} \\
K\left(L_{t}^{M}\right)^{\gamma} & \text { if } & L_{t}^{M} \geqslant \widehat{L}_{M}
\end{array}\right.
$$

Since $\gamma<1, I_{t}^{M}$ is concave in $L_{t}^{M}$ for $L_{t}^{M}>\widehat{L}_{M}$. Note that if the manufacturing sector operates under the traditional technology, no infrastructure is needed so the wage tax rate is zero. The level of after-tax income in region $M$ as a function of the size of the labour force is illustrated by the curve $I_{t}^{M}$ in Figure 1.

\section{Agricultural Sector in Region $R$}

Labour supply in region $R, L_{t}^{R}$, is divided between employment in agriculture, $L_{t}^{A}$, and natural resources, $L_{t}^{N}$. Total population is normalized to 1 , so $1-L_{t}^{M}=L_{t}^{R}=L_{t}^{A}+L_{t}^{N}$. Production of agricultural output $A_{t}$ exhibits constant returns to scale according to:

$$
A_{t}=L_{t}^{A}=L_{t}^{R}-L_{t}^{N}
$$

Residents of both regions derive utility from agricultural goods and manufacturing goods according to $u_{t}^{j}=X_{t}^{j}+v\left(A_{t}^{j}\right)$, with $v^{\prime}\left(A_{t}^{j}\right)>0, v^{\prime \prime}\left(A_{t}^{j}\right)<0$ and $v^{\prime}(0) \rightarrow \infty$, for $j=M, R$. Let $w_{t}^{A}$ denote the wage rate in the agricultural sector. It will be equal to the price of agricultural goods $P_{t}^{A}$. The budget constraint of consumers in region $j$ can be written as $X_{t}^{j}+P_{t}^{A} A_{t}^{j}=I_{t}^{j}$ where $I_{t}^{j}$ denotes disposal income in region $j$. Utility maximization yields equal per capita consumption of agricultural goods in each region satisfying $P_{t}^{A}=v^{\prime}\left(A_{t}^{*}\right)$, and therefore:

$$
w_{t}^{A}=v^{\prime}\left(A_{t}^{*}\right)=v^{\prime}\left(L_{t}^{R}-L_{t}^{N}\right)
$$

For convenience, we assume that $v\left(A_{t}\right)=H \ln \left(A_{t}\right)$ with $H>0$, so $v^{\prime}\left(A_{t}\right)=H / A_{t}$. Since per capita consumption of agricultural goods will be equalized across regions, the migration equilibrium will not depend on agricultural output. 
Natural Resource Sector in Region R

The extraction of natural resources uses labour and manufacturing goods as inputs. The process is assumed to require a fixed amount of labour $L_{t}^{N}$ per unit of extraction $Z_{t}$, so $L_{t}^{N}=Z_{t}$, and an amount of the manufacturing good that depends on the remaining stock of the resource according to:

$$
X_{t}^{N}=\phi\left(S_{t}\right) Z_{t} \equiv C\left(S_{t}, Z_{t}\right)
$$

where $S_{t}$ denotes the stock of natural resources at time $t, \phi^{\prime}\left(S_{t}\right)<0$ so the cost of extraction increases as the stock is depleted, and $\dot{S}_{t}=-Z_{t}{ }^{3}$

Let $P_{t}^{N}$ denote the unit price of the natural resource. We assume that it increases exogenously over time at a constant rate. Since labour is freely mobile between the agricultural and natural resource sectors, both located in region $R$, the wage rate in the natural resource sector will equal that in the agricultural sector, so the wage rate in region $R$ is given by $w_{t}^{R}=w_{t}^{A}$. The rent generated from the extraction of natural resources $\Pi_{t}$ is:

$$
\Pi_{t}=P_{t}^{N} Z_{t}-w_{t}^{R} L_{t}^{N}-\phi\left(S_{t}\right) Z_{t}=P_{t}^{N} Z_{t}-w_{t}^{R} Z_{t}-\phi\left(S_{t}\right) Z_{t}
$$

$\Pi_{t}$ will be shared between labour in region $R$ and resource producers as specified below.

\section{Equilibrium under Decentralization}

In this section, we characterize the level of infrastructure investment, the level of natural resource extraction and the allocation of labour under decentralization. In setting their policies, we assume for simplicity that regional governments take as given the allocation of labour across regions. They do not foresee the impact of their policies on migration. Considering forward-looking governments with respect to migration would complicate the analysis considerably without adding much insight. Our main objective is to examine the distortion in the extraction rate chosen by the region $R$ government relative to that which is optimal from the perspective of the federation. The extraction rate will be distorted because the resource region has no incentive to take into account the impact of resource extraction on labour productivity in the manufacturing region. If we assumed that the government of the resource region took into account the impact of its policy on labour 
allocation, the distortion would be amplified. The government of region $R$ does however anticipate the impact of resource extraction on resource depletion.

\section{Infrastructure Investment in Region $M$}

Regional governments choose their policies to maximize total after-tax income in the current period. ${ }^{4}$ If the manufacturing sector uses the modern technology, the problem of the region $M$ government, using $(9)$ and $\gamma=1 /(\sigma(1-\alpha))-1$ is:

$$
\max _{\tau_{M}}\left(1-\tau_{M}\right) w_{t}^{M} L_{t}^{M}=\left(1-\tau_{M}\right) D^{\frac{1}{1-\alpha}} \tau_{M}^{\frac{\alpha}{1-\alpha}}\left(L_{t}^{M}\right)^{\frac{1}{\sigma(1-\alpha)}}
$$

The solution to this problem gives $\tau_{M}^{*}=\alpha$, so the optimal tax rate is independent of the allocation of labour. Using the government budget constraint, we have $G_{t}^{*}=\alpha X_{t}$.

\section{Natural Resource Extraction in Region $R$}

The region $R$ government values equally rents to labour and to producers, who are also assume to be residents of region $R$, and sets the extraction level to maximize the discounted flow of total regional income anticipating the impact of extraction on the natural resource stock. Using (12) and (13), period-t income is:

$$
Y_{t}^{R}=w_{t}^{R} L_{t}^{R}+\Pi_{t}=P_{t}^{N} Z_{t}-\phi\left(S_{t}\right) Z_{t}+v^{\prime}\left(L_{t}^{R}-Z_{t}\right)\left(L_{T}^{R}-Z_{t}\right)
$$

Using $v^{\prime}\left(A_{t}\right)=H / A_{t}=H /\left(L_{t}^{R}-Z_{t}\right)$ and $\dot{S}_{t}=-Z_{t}$, the Lagrangian of the government problem is:

$$
\mathcal{L}\left(Z_{t}, S_{t}\right)=\int e^{-\rho t}\left[P_{t}^{N} Z_{t}-\phi\left(S_{t}\right) Z_{t}+H\right] d t-\int \lambda_{t}\left[Z_{t}+\dot{S}_{t}\right] d t
$$

Assumption $v^{\prime}\left(A_{t}\right)=H / A_{t}$ implies that income in the agricultural sector is independent of the allocation of labour. Noting that

$$
\int \lambda_{t}\left[Z_{t}+\dot{S}_{t}\right] d t=\int \lambda_{t} Z_{t} d t+\int \lambda_{t} \dot{S}_{t} d t=\int \lambda_{t} Z_{t} d t+\left.\lambda_{t} S_{t}\right|_{0} ^{\infty}-\int \dot{\lambda_{t}} S_{t} d t
$$

and using the transversality condition $\left.\lambda_{t} S_{t}\right|_{0} ^{\infty}=0$, (15) can be rewritten as:

$$
\mathcal{L}\left(Z_{t}, S_{t}\right)=\int e^{-\rho t}\left[P_{t}^{N} Z_{t}-\phi\left(S_{t}\right) Z_{t}+H\right] d t-\int \lambda_{t} Z_{t} d t+\int \dot{\lambda_{t}} S_{t} d t
$$


The first-order conditions are:

$$
\begin{gathered}
\frac{\partial \mathcal{L}}{\partial Z_{t}}=e^{-\rho t}\left[P_{t}^{N}-\phi\left(S_{t}\right)\right]-\lambda_{t}=0 \\
\frac{\partial \mathcal{L}}{\partial S_{t}}=-e^{-\rho t} \phi^{\prime}\left(S_{t}\right) Z_{t}+\dot{\lambda_{t}}=0
\end{gathered}
$$

From (17), the discounted increase in income resulting from higher extraction equals the shadow value of one unit of the resource. Equivalently, the marginal value of extracting one more unit of resource now is set equal to the shadow value of a unit of stock. By (18), the stock of natural resources evolves such that the discounted increase in the cost of extraction equals the change in the shadow value of a unit of stock. Let $Z^{*}\left(P_{t}^{N}, S_{t}\right)$ denote the solution to this problem. Using $Z^{*}\left(P_{t}^{N}, S_{t}\right)$, total income in region $R$ equals:

$$
Y_{t}^{R^{*}}=P_{t}^{N} Z_{t}^{*}-\phi\left(S_{t}\right) Z_{t}^{*}+H \equiv Y^{R^{*}}\left(P_{t}^{N}, S_{t}\right)
$$

To provide additional interpretation for the solution of the government problem in region $R$, combine (17), (18) and (19) to derive a version of Hotelling's rule: ${ }^{5}$

$$
\frac{\dot{Y}_{z}^{R, t}}{Y_{z}^{R, t}}=\rho+\frac{C_{s}\left(S_{t}, Z_{t}\right)}{Y_{z}^{R, t}}
$$

Eq. (22) indicates that, on the chosen extraction path, the rate of change in the net benefits of extracting the resource from the perspective of region $R$ equals the rate of time preference plus the effect of depleting the resource stock on the cost of extraction.

A proportion $0 \leqslant \theta \leqslant 1$ of the rent is assumed to be taxed by the regional government and shared equally among labour located in region $R$. The remaining proportion $1-\theta$ accrues to resource producers. The parameter $\theta$ is assumed to be determined exogenously. Note that our results do not require that producers capture part of the rent. They will hold in the special case where $\theta=1$ so the entire rent is captured by labour. The per capita income of the resident workers in region $R$ is:

$$
I_{t}^{R}=w_{t}^{R}+\theta \frac{\Pi_{t}}{L_{t}^{R}}=(1-\theta) v^{\prime}\left(L_{t}^{R}-Z_{t}\right)+\frac{\theta}{L_{t}^{R}} Y^{R}\left(P_{t}^{N}, S_{t}\right)
$$

where the last equality follows from $\Pi_{t}=Y_{t}^{R}-w_{t}^{R} L_{t}^{R}$ by (13) and (19) and $w_{t}^{R}=$ $v^{\prime}\left(L_{t}^{R}-Z_{t}\right)$ by (12). Using $v^{\prime}\left(A_{t}\right)=H /\left(L_{T}^{R}-Z_{t}\right)$, this expression for $I_{t}^{R}$ can be written:

$$
I_{t}^{R}=(1-\theta) \frac{H}{1-L_{t}^{M}-Z\left(P_{t}^{N}, S_{t}\right)}+\frac{\theta}{1-L_{t}^{M}} Y^{R}\left(P_{t}^{N}, S_{t}\right) \equiv I^{R}\left(1-L_{t}^{M}, P_{t}^{N}, S_{t}, \theta\right)
$$


From (23), we can readily verify that $\partial I_{t}^{R} / \partial L_{t}^{M}>0$ and $\partial^{2} I_{t}^{R} / \partial\left(L_{t}^{M}\right)^{2}>0$. Hence, we have the following proposition.

Proposition 1. Assuming that i) $v(A)=H \ln (A)$, and that ii) the government of region $R$ chooses the extraction rate to maximize regional income taking as given the allocation of population across regions $L_{t}^{R}=1-L_{t}^{M}$, then $I_{t}^{R}$ is increasing and convex in $L_{t}^{M}$.

Per capita income in region $R, I_{t}^{R}$, as a function of $L_{t}^{M}$ is depicted in Figure 1 for given values of $P_{t}^{N}, S_{t}$ and $\theta$.

\section{Interregional Allocation of Labour}

At any point in time, there will be a migration flow towards the region with the highest per capita disposable income, as specified below. The long-run equilibrium allocation of labour will be such that incomes are fully equalized across regions. However, for any given resource stock $S_{t}$, there can be multiple equilibria, as illustrated in Figure 1. Depending on the initial distribution of labour, the economy may converge to equilibrium $E_{1}$ where the manufacturing sector in region $M$ operates under the traditional technology, or to equilibrium $E_{3}$ in which the manufacturing sector uses the modern technology. In contrast to equilibria $E_{1}$ and $E_{3}$ which are stable, the equilibrium denoted by $E_{2}$ is unstable. Starting at $E_{2}$, a small increase in $L_{t}^{M}$ will induce further migration towards region $M$ and convergence to allocation $E_{3}$. Similarly, a small decrease in $L_{t}^{M}$ from $E_{2}$ will lead to convergence to $E_{1}$.

Per capita income is higher in both regions at $E_{3}$ than at $E_{1}$. This reflects the fact that the manufacturing sector uses the modern technology at $E_{3}$. The higher productivity of labour that results from increasing returns-to-scale in manufacturing leads to higher per capita income in both regions.

Transitional dynamics will involve a migration flow towards the region where the level of utility, or disposable income, is highest. However, labour mobility is assumed to be imperfect in the sense that the migration of workers requires time so that disposable income will not be equalized instantaneously. This is captured by assuming that the flow 
of migration towards region $M$ at time $t$ is equal to the following:

$$
\dot{L}_{t}^{M}=\eta\left(I_{t}^{M}-I_{t}^{R}\right)
$$

where $\eta$ reflects the speed of adjustment in the inter-regional allocation of labour. Using (11) and (23) for $I_{t}^{M}$ and $I_{t}^{R},(24)$ becomes:

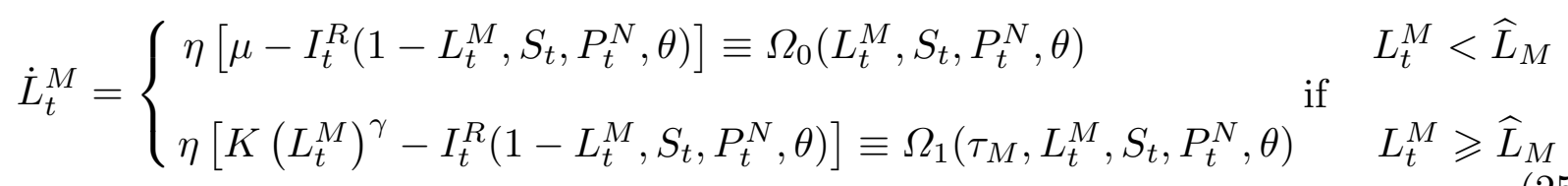

Differentiating $\Omega_{1}(\cdot)$ in $(25)$ and using (11), we obtain:

$$
\frac{\partial^{2} \Omega_{1}}{\partial\left(L_{t}^{M}\right)^{2}}=\eta\left[\frac{\partial^{2} I_{t}^{M}}{\partial\left(L_{t}^{M}\right)^{2}}-\frac{\partial^{2} I_{t}^{R}}{\partial\left(L_{t}^{M}\right)^{2}}\right]<0
$$

where the sign follows from noting that $I_{t}^{M}$ is concave in $L_{t}^{M}$ by (11) and $I_{t}^{R}$ is convex in $L_{t}^{M}$ by Proposition 1 . Therefore, $\Omega_{1}(\cdot)$ is concave in $L_{t}^{M}$ as depicted in Figure 2.

For a given stock of natural resource $S_{t}$, migration towards region $M$ will be positive $\left(\Omega_{1}>0\right)$ if the population of region $M$ is within the interval $\left[\underline{L}^{M}, \bar{L}^{M}\right]$, where we have assumed that $\underline{L}^{M}>\widehat{L}^{M}$. For values of $L_{t}^{M}$ below $\underline{L}^{M}$, economies of scale in manufacturing are relatively small (or non-existent if $L_{t}^{M}<\widehat{L}^{M}$ ) so the wage rate in region $M$ is relatively low. For values of $L_{t}^{M}$ above $\bar{L}^{M}, L_{t}^{R}$ is relatively low so the wage rate is relatively high. Thus, for values of $L_{t}^{M}$ outside of $\left[\underline{L}^{M}, \bar{L}^{M}\right]$, there is a flow of migration towards region $R$. The bounds of this interval, $\underline{L}^{M}$ and $\bar{L}^{M}$, are the solutions to $\Omega_{1}\left(\tau_{M}, L_{t}^{M}, S_{t}, P_{t}^{N}, \theta\right)=$ 0 . Using the expression that characterizes $\Omega_{1}$ above, we can derive:

$$
\frac{\partial \underline{L}_{t}^{M}}{\partial S_{t}}>0, \quad \text { and } \quad \frac{\partial \bar{L}_{t}^{M}}{\partial S_{t}}<0
$$

This implies that a higher level of the natural resource stock $S_{t}$ reduces the size of the interval $\left[\underline{L}^{M}, \bar{L}^{M}\right]$ for which migration towards region $M$ is positive and shifts the curve $\Omega_{1}\left(\tau_{M}, L_{t}^{M}, S_{t}, P_{t}^{N}, \theta\right)$ downwards in the $\left(L_{t}^{M}, \Omega_{1}\right)$-space. Thus, we have the following:

Proposition 2. Assuming that $(1 /(\sigma(1-\alpha)))-1 \equiv \gamma<1$, the following holds:

i. $\Omega_{1}\left(\tau_{M}, L_{t}^{M}, S_{t}, P_{t}^{N}, \theta\right)$ is concave in $L_{t}^{M}$; and 
ii. $\partial \underline{L}_{t}^{M} / \partial S_{t}>0$ and $\partial \bar{L}^{M} / \partial S_{t}<0$, so an increase in $S_{t}$ reduces the size of the interval $\left[\underline{L}^{M}, \bar{L}^{M}\right]$ for which migration towards region $M$ is positive.

The values of $\underline{L}^{M}$ and $\bar{L}^{M}$ correspond to a specific level of the stock $S_{t}$. By varying $S_{t}$ we can trace out all combinations of $S_{t}$ and $L_{t}^{M}$ for which $\Omega_{1}\left(\tau_{M}, L_{t}^{M}, S_{t}, P_{t}^{N}, \theta\right)=0$. The curve of $\Omega_{1}\left(\tau_{M}, L_{t}^{M}, S_{t}, P_{t}^{N}, \theta\right)=0$ is represented in the $\left(L_{t}^{M}, S_{t}\right)$-space in Figure 3 . The curve of $\Omega_{0}\left(L_{t}^{M}, S_{t}, P_{t}^{N}, \theta\right)=0$ and transitional dynamics are also shown in Figure 3 .

For initial combinations of $L_{t}^{M}$ and $S_{t}$ located below the $\Omega_{1}=0$ curve, there will be a positive migration flow towards region $M$ and the economy will converge in the longrun towards $E_{3}$. If the initial combination of $L_{t}^{M}$ and $S_{t}$ lies above the $\Omega_{1}=0$ curve, the economy may converge towards $E_{1}$ or $E_{3}$ depending on whether the transition path crosses the $\Omega_{1}=0$ curve or not. The economy is more likely to converge to $E_{1}$ where the manufacturing sector uses the traditional technology if the initial stock of natural resource and the initial proportion of population located in region $R$ are relatively high.

Using (23), it is straightforward to show that $\partial \Omega_{1}(\cdot) / \partial P_{t}^{N}<0$. An increase in the price of natural resources will increase the rent captured by the residents of region $R$, both because the rent per unit of extraction increases and because a higher extraction rate will be chosen. In turn, this will induce a larger migration flow towards region $R$ for any given value of the stock of natural resources $S_{t}$ and any initial allocation of labour $\left(L_{t}^{M}, L_{t}^{R}\right)$. This also implies that if the price of natural resource increases, the set of initial conditions over $\left(L_{t}^{M}, S_{t}\right)$ under which the economy converges to equilibrium $E_{3}$ in the long-run will become smaller. In the short-run however, that is, for a given inter-regional allocation of labour, total income in the federation will increase.

From (23), we can also readily verify that $\partial \Omega_{1}(\cdot) / \partial \theta<0$. Since the government of region $R$ is assumed to set the extraction rate to maximize total regional income, the share of the rent captured by labour $\theta$ does not affect the extraction rate. However, it does affect the incentives to migrate towards region $R$. Thus, an increase in $\theta$ tends to shrink the set of initial conditions over $\left(L_{t}^{M}, S_{t}\right)$ for which the economy converges to $E_{3}$, and vice-versa. In fact, for sufficiently low values of $\theta$, equilibrium $E_{1}$ may not exist at all. To see this, simply note that for a given extraction rate, per capita income in region $R$ decreases with 
the value of $\theta$. As a result, as $\theta$ decreases, the curve labeled $I_{t}^{R}$ in Figure 1 will shift downwards. For a sufficiently large shift, equilibria $E_{1}$ and $E_{2}$ may disappear, leading to a unique equilibrium.

The following proposition summarizes the main results of this section.

Proposition 3. Under decentralization, the economy exhibits the following properties:

$i$. There exists multiple equilibrium allocations of labour each characterized by equal per capita disposable income in both regions;

ii In the high-income equilibrium, the manufacturing sector uses the modern technology and generates increasing returns-to-scale;

iii. An increase in the price of natural resources shrinks the set of initial conditions over $\left(L_{t}^{M}, S_{t}\right)$ for which the economy converges to the high-income equilibrium $E_{3}$. Total income in the federation increases in the short run but may decrease in the long run; and

$i v$. If the share of resource rents captured by producers increases, the set of conditions over $\left(L_{t}^{M}, S_{t}\right)$ for which the economy converges to the high-income equilibrium becomes larger.

\section{The Constrained Federal Optimum}

The constrained social optimum from the perspective of the federation is defined by the tax rate in region $M$ and the path of natural resource extraction in region $R$ that maximize the discounted flow of aggregate income in both regions. We characterize a constrained optimum in which extraction efficiency is achieved but not necessarily full efficiency in the allocation of labour, as discussed below. Total income for both regions in period $t$ is:

$$
Y_{t}=K\left(L_{t}^{M}\right)^{\gamma+1}+P_{t}^{N} Z_{t}-\phi\left(S_{t}\right) Z_{t}+H
$$

The first term on the right side of (27) is total after-tax income in region $M$, the second and third terms correspond to total income in the resource sector including the share of rents captured by producers, and $H$ is total income in the agricultural sector. Because of the specific form assumed for $v(A)$, total income in the agricultural sector is independent of $L^{A}$. We therefore fix $L^{A}$ at some arbitrary level, which implies that $d L_{t}^{M}+d Z_{t}=0$. 
The Lagrangian for the federal problem, given the constraint $\dot{S}_{t}=-Z_{t}$, is:

$$
\mathcal{L}\left(\tau_{M}, Z_{t}, S_{t}\right)=\int e^{-\rho t}\left[K\left(L_{t}^{M}\right)^{\gamma+1}+P_{t}^{N} Z_{t}-\phi\left(S_{t}\right) Z_{t}+H\right] d t-\int \lambda_{t}\left[Z_{t}+\dot{S}_{t}\right] d t
$$

Using (16) and $\left.\lambda_{t} S_{t}\right|_{0} ^{\infty}=0$, this can be rewritten as:

$$
\mathcal{L}(\cdot)=\int e^{-\rho t}\left[K\left(L_{t}^{M}\right)^{\gamma+1}+P_{t}^{N} Z_{t}-\phi\left(S_{t}\right) Z_{t}+H\right] d t-\int \lambda_{t} Z_{t} d t+\int \dot{\lambda_{t}} S_{t} d t
$$

Note that this problem is not subject to the migration condition. Since $L^{A}$ is taken as given, $d L_{t}^{M}=-d Z_{t}$, so the time-path of $Z_{t}$ determines the inter-regional labour allocation. It is straightforward to verify that the optimal tax rate is $\tau_{M}^{*}=\alpha$, the same as under decentralized policy-making. The first-order conditions on $Z_{t}$ and $S_{t}$ are (using $d L_{t}^{M}=$ $\left.-d Z_{t}\right)$

$$
\frac{\partial \mathcal{L}}{\partial Z_{t}}=e^{-\rho t}\left[P_{t}^{N}-\phi\left(S_{t}\right)-K(\gamma+1)\left(L_{t}^{M}\right)^{\gamma}\right]-\lambda_{t}=0
$$

and (18) characterizing the evolution of the natural resource stock. Eq. (28) indicates that extraction at time $t$ is set so that the discounted increase in aggregate income in region $R$ that results from increasing the extraction rate minus the reduction in total income in region $M$ resulting from the associated decrease in labour ( since $d L_{t}^{M}=-d Z_{t}$ ) is set equal to the shadow value of a unit of natural resources at time $t$.

Let $Z^{* *}\left(P_{t}^{N}, S_{t}\right)$ denote the solution to this problem. By comparing (28) to (17), it is clear that the extraction decision of the government of region $R$ under decentralization is distorted relative to the constrained federal optimum. Condition (28) includes an additional term, $K(\gamma+1)\left(L_{t}^{M}\right)^{\gamma}>0$, corresponding to the impact of increasing $Z_{t}$, and the associated reallocation of labour towards region $R$, on the marginal product of labour in region $M$. The fact that the government of region $R$ does not take this effect into account in its extraction decision implies that there is a tendency to over-extract the resource relative to the constrained federal optimum. In turn, this tendency to over-extract under decentralization makes it more likely that the economy converges to the low-income equilibrium in the long-run.

As under decentralization, we can combine (28) and (18) to derive a modified version of Hotelling's rule characterizing the constrained federal optimum: ${ }^{6}$

$$
\frac{\dot{Y}_{z}^{t}}{Y_{z}^{t}}=\rho+\frac{C_{s}\left(S_{t}, Z_{t}\right)}{Y_{z}^{t}}
$$


Eq. (31) is similar to the Hotelling's rule derived under decentralization, although here the net marginal benefit of extracting takes into account the reduction in the marginal product of labour in region $M$ that results from shifting labour to the resource sector. It is therefore a modified version of the standard Hotelling's rule since it integrates the interregional externality present in our model.

Note that in addition to the inefficiency of extraction under decentralization, the equilibrium is also subject to migration inefficiencies. Because of agglomeration externalities in the manufacturing sector, there will be too little labour located in region $M$ even in the high-income equilibrium (i.e. at $E_{3}$ in Figure 1). That will be the case even in the absence of any resource extraction. Moreover, as long as workers capture part of the natural resource rent, there will be incentives for rent-seeking migration towards region $R$, which will further distort the allocation of labour. These inefficiencies are exacerbated by the extraction inefficiency. The constrained federal optimum characterized above achieves extraction efficiency, but not migration efficiency.

The main results of this section are as follows.

\section{Proposition 4.}

$i$. The extraction decision of the government of region $R$ is distorted relative to the constrained federal optimum, leading to a tendency to over-extract the resource under decentralization; and

ii. In the constrained federal optimum, the inter-regional allocation of labour $L_{t}^{M}$ and the stock of natural resources $S_{t}$ evolve over time according to (31), $\dot{S}_{t}=-Z_{t}$, and in the long-run $S_{t} \rightarrow 0, Z_{t} \rightarrow 0$ and $L_{t}^{M} \rightarrow 1-L_{t}^{A}$.

\section{Conclusion}

This paper analyzed a resource extraction problem in a federal setting with decentralized natural resource management and inter-regional labour mobility. The analysis showed that there are multiple equilibrium allocations of labour towards which the economy may converge in the long-run. Under decentralization, the government of the resource region tends to set an inefficiently high level of extraction relative to the constrained federal optimum, which makes convergence to the low-income equilibrium more likely. In contrast, 
the optimal extraction path from the perspective of the whole federation takes into account the impact of resource extraction on manufacturing production.

Two extensions would be worth pursuing. First, we could examine how a central government might intervene to induce the socially optimal levels of extraction and migration. Migration is inefficient because productivity in manufacturing is increasing in the number of workers and this benefit is not internalized in wages. Rents obtained by workers in the resource-producing region exacerbates this externality. The conventional remedy for migration inefficiency is a system of equalizing interregional transfers deployed by the federal government. Federal policies to correct the inefficiency of regional resource extraction are more controversial. In principle, the federal government could impose a tax on resource extraction to internalize this externality, though this would entail federal interference with regional resource extraction policies. The federal government could also affect migration and resource extraction indirectly by spending on infrastructure in the manufacturing region which would increase labour productivity and lead to greater employment in manufacturing.

Second, we could examine the incentives that the resource region might have to use some of the resource rents to invest in infrastructure in order to develop a manufacturing sector. Doing so would contribute to diversifying the resource region's economy but would tend to dilute economies of scale in the manufacturing region with potentially adverse effects on aggregate income in the federation. 


\section{Endnotes}

1. The structure of the economy with a manufacturing sector exhibiting increasing returns to scale and a constant returns to scale agricultural sector is similar to that in Krugman (1991). Sachs and Warner (1999) consider a similar structure although they do not refer to the two sectors as manufacturing and agriculture.

2. Note that the after-tax wage rate appears on the left side of the condition above, rather than simply the wage rate, since the modern technology will only be adopted if workers are willing to move to the modern sector and that requires that the after-tax wage rate be greater than the marginal product of labour under the traditional technology.

3. Our main results do not rely critically on the assumption that the extraction cost depend on the remaining stock. Alternatively, we could consider a stock-independent cost function that would be convex in the instantaneous extraction rate.

4. Since the allocation of population is taken as given by regional governments, choosing policies to maximize total income or per capita income is equivalent.

5. Rearrange (17) and differentiate with respect to $t$ to obtain $\rho e^{\rho t} \lambda_{t}+e^{\rho t} \dot{\lambda}_{t}=\dot{P}_{t}^{N}-$ $\phi^{\prime}\left(S_{t}\right) \dot{S}_{t}$. Substituting (17) and (18) on the left-hand side gives:

$$
\rho\left[P_{t}^{N}-\phi\left(S_{t}\right)\right]+\phi^{\prime}\left(S_{t}\right) Z_{t}=\dot{P}_{t}^{N}-\phi^{\prime}\left(S_{t}\right) \dot{S}_{t}
$$

Differentiate $Y_{t}^{R *}$ in (19) by $Z_{t}$ to give $Y_{z}^{R, t}$ and then by $t$ to get $\dot{Y}_{z}^{R, t}=\dot{P}_{t}^{N}-\phi^{\prime}\left(S_{t}\right) \dot{S}_{t}$. Note also that

$$
\frac{\partial C\left(S_{t}, Z_{t}\right)}{\partial S_{t}} \equiv C_{s}\left(S_{t}, Z_{t}\right)=\phi^{\prime}\left(S_{t}\right) Z_{t}
$$

Using these expressions, rewrite (20) as $\rho Y_{z}^{R, t}+C_{s}\left(S_{t}, Z_{t}\right)=\dot{Y}_{z}^{R, t}$, which gives (22).

6. The derivation is similar to that of equation (22). Differentiating (28) with respect to $t$, and substituting (28) and (18) in the resulting equation gives:

$\rho\left[P_{t}^{N}-\phi\left(S_{t}\right)-K(\gamma+1)\left(L_{t}^{M}\right)^{\gamma}\right]+\phi^{\prime}\left(S_{t}\right) Z_{t}=\dot{P}_{t}^{N}-\phi^{\prime}\left(S_{t}\right) \dot{S}_{t}-K(\gamma+1) \gamma\left(L_{t}^{M}\right)^{\gamma-1} \dot{L}_{t}^{M}$

Differentiating (27) by $Z_{t}$ to give $Y_{z}^{t}$ and then by $t$, we obtain:

$$
\dot{Y}_{z}^{t}=\dot{P}_{t}^{N}-\phi^{\prime}\left(S_{t}\right) \dot{S}_{t}-K(\gamma+1) \gamma\left(L_{t}^{M}\right)^{\gamma-1} \dot{L}_{t}^{M}
$$

Using (21) and (30) in (29) gives (31). 


\section{References}

Albouy, D. (2012), 'Evaluating the Efficiency and Equity of Federal Fiscal Equalization', Journal of Public Economics 96, 824-39.

Baldwin, R. and P. Krugman (2004), 'Agglomeration, Integration, and Tax Harmonization', European Economic Review 48, 1-23.

Boadway, R. and F. Flatters (1982), 'Efficiency and Equalization Payments in a Federal System of Government: A. Synthesis and Extension of Recent Results', Canadian Journal of Economics 15, 613-33.

Bucovetsky, S. (2005), 'Public Input Competition', Journal of Public Economics 89, 176387.

Corden, W. M. and J.P. Neary (1982), 'Booming Sector and De-industrialisation in a Small Open Economy', Economic Journal 92, 825-48.

Flatters, F., V. Henderson and P. Mieszkowski (1974), 'Public Goods, Efficiency, and Regional Fiscal Equalisation', Journal of Public Economics 3, 99-112.

Gordon, R. (1983), 'An Optimal Taxation Approach to Fiscal Federalism', Quarterly Journal of Economics 97, 567-86.

Krugman, P. (1987), 'The Narrow Moving Band, the Dutch Disease, and the Competitive Consequences of Mrs. Thatcher: Notes on Trade in the Presence of Dynamic Scale Economies', Journal of Development Economics 27, 41-55.

Krugman, P. (1991), 'Increasing Returns and Economic Geography', Journal of Political Economy 99, 483-99.

Mitsui, K. and M. Sato (2001), 'Ex Ante Free Mobility, Ex Post Immobility, and TimeConsistent Policy in a Federal System', Journal of Public Economics 82, 445-60.

Murphy, K., A. Shleifer and R. Vishny (1989), 'Industrialization and the Big Push', Journal of Political Economy 97, 1003-1026.

Raveh, O. (2012), 'Dutch Disease, Factor Mobility, and the Alberta Effect The Case of Federations', Hebrew University of Jerusalem, mimeo.

Sachs, J. and A. Warner (1999), 'The Big Push, Natural Resource Booms and Growth', Journal of Development Economics 59, 43-76.

Sachs, J. and A. Warner (2001), 'The Curse of Natural Resources', European Economic Review 45, 827-838.

van der Ploeg, F. (2011), 'Natural Resources: Curse or Blessing?', Journal of Economic Literature 49, 366-420. 


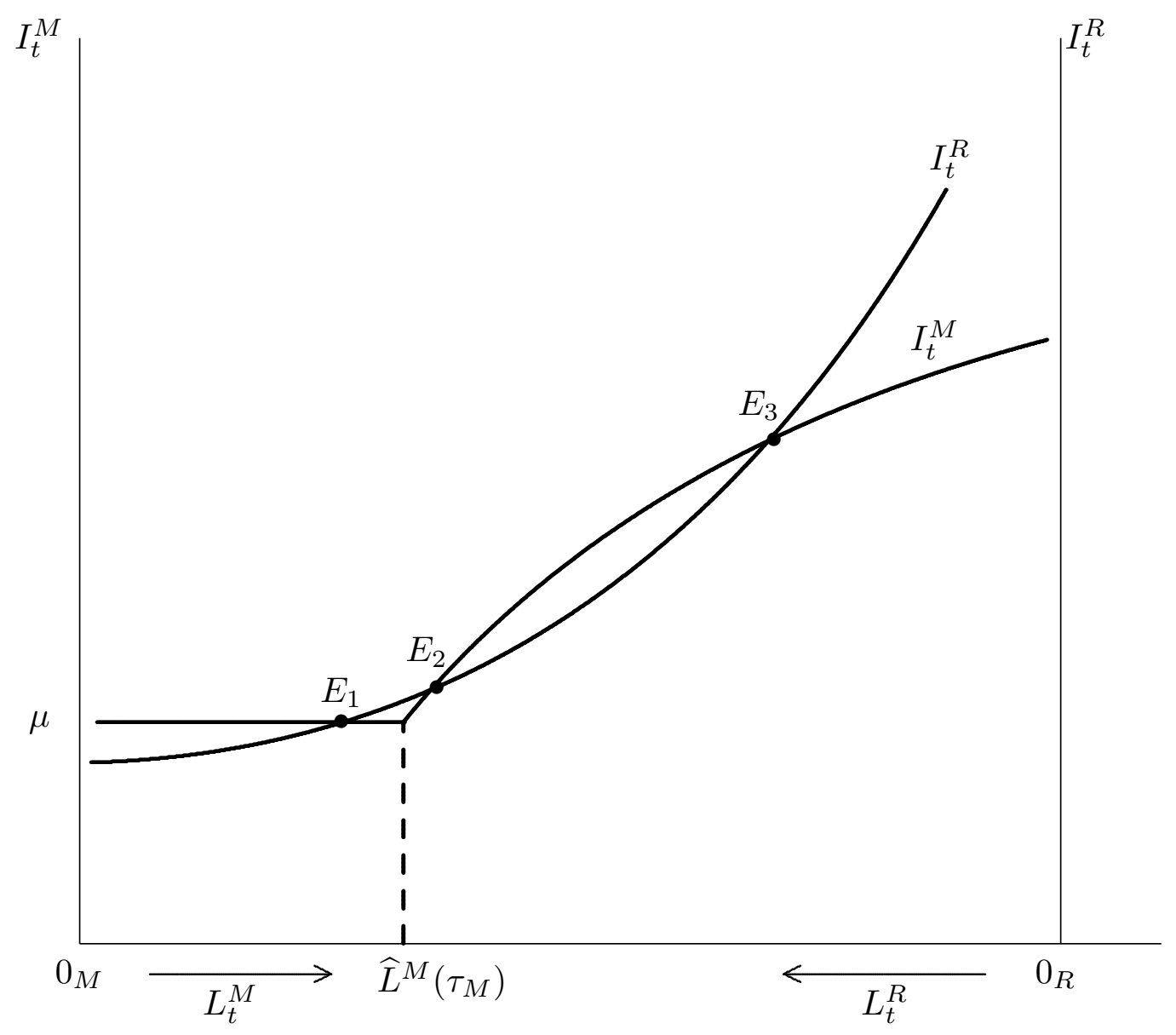

Figure 1 


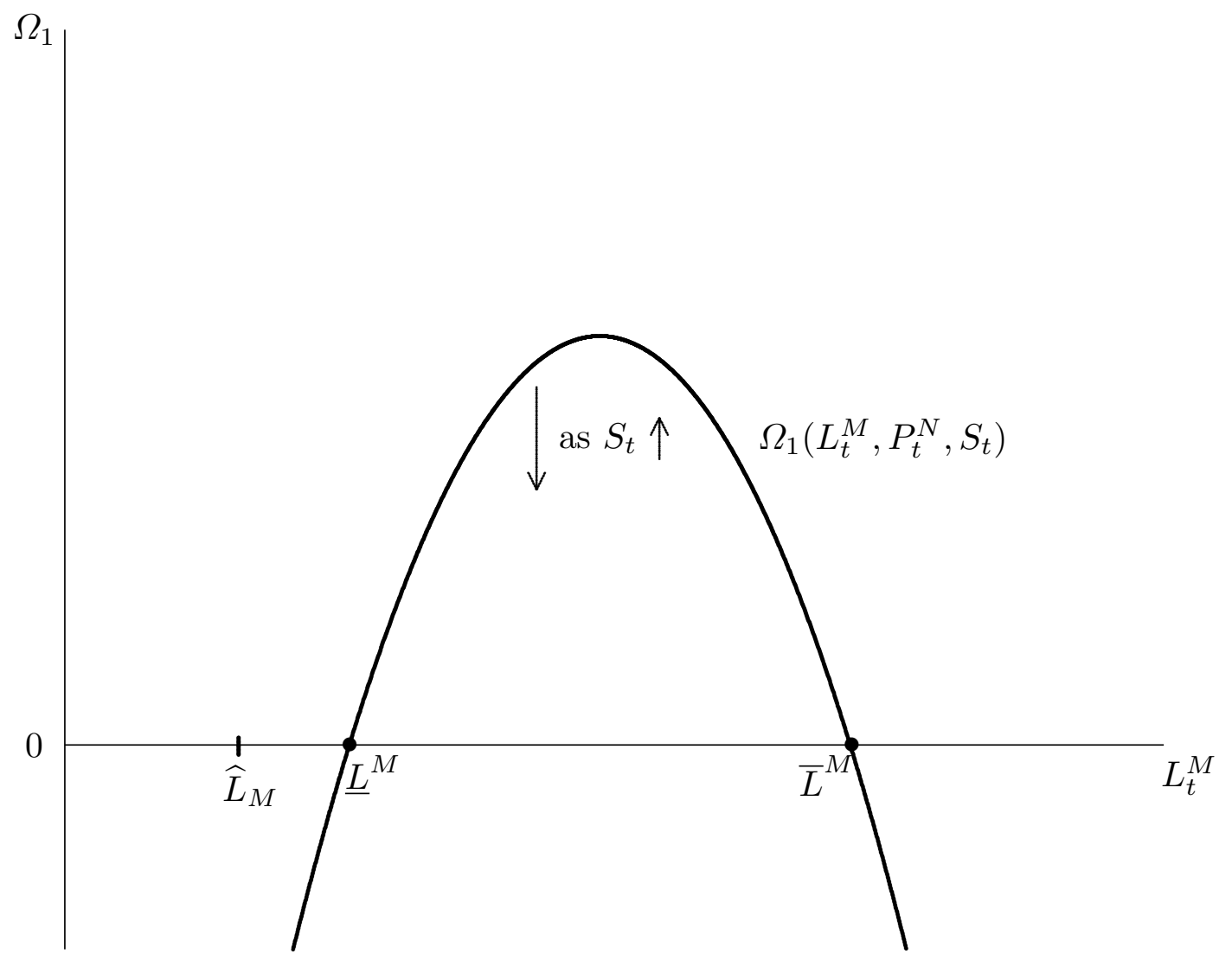

Figure 2 


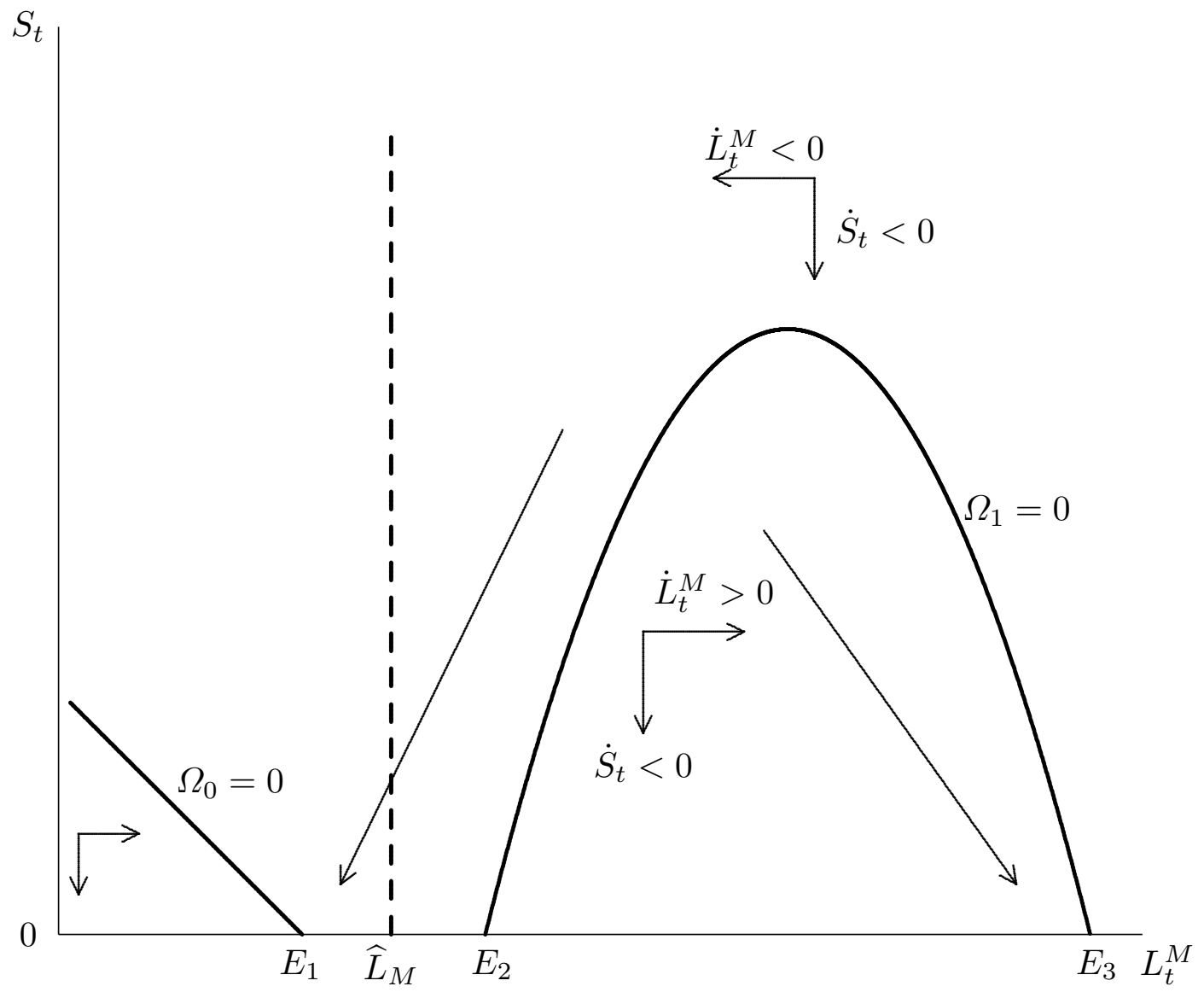

Figure 3 